\title{
A NEW GENUS AND SPECIES OF ERIOPHYOID MITES (ACARI: ERIOPHYOIDEA: DIPTILOMIOPIDAE) ON PHYLLOSTACHYS IRIDESCENS (POACEAE) FROM HUNGARY
}

\author{
GÉza Ripka ${ }^{1}$, Jenő Kontschán ${ }^{2}$ and András Neményi ${ }^{3}$ \\ ${ }^{1}$ National Food Chain Safety Office, Directorate of Plant Protection \\ Soil Conservation and Agri-environment, Department of Pest Management Development and \\ Coordination, H-1118 Budapest, Budaörsi út 141-145, Hungary. E-mail: RipkaG@nebih.gov.hu \\ ${ }^{2}$ Plant Protection Institute, Agricultural Research Centre of Hungarian Academy of Sciences, \\ H-1022 Budapest, Herman Ottó út 15, Hungary \\ ${ }^{3}$ Institute of Horticulture, Szent István University \\ H-2100 Gödöllő, Páter Károly str. 1, Hungary
}

A new diptilomiopid genus and species, Mucotergum nigrum Ripka gen. et sp. n., associated with Phyllostachys iridescens (Poaceae), are described from Hungary. The prodorsal shield and dorsal semiannuli covered by mucus-like substance. Taxonomically relevant morphological details are illustrated.

Key words: Prostigmata, Diptilomiopidae, new taxa, Mucotergum, cock bamboo, Poaceae, Hungary.

\section{INTRODUCTION}

The plant family Poaceae (former Gramineae) is a dominant feature of the Hungarian flora with 229 recognized species in 72 genera (KIRÁLY 2009), representing $8.4 \%$ of vascular plants in Hungary. Knowledge on the eriophyoid mites of poaceous hosts is found wanting. In Hungary only 14 eriophyoid species were recorded from 15 poaceous hosts (RIPKa 2007, 2008). Among several Phyllostachys species of Asian origin, cock bamboo (Phyllostachys iridescens C. Y. Yao et S. Y. Chen) (Poaceae) is native to Eastern China (i.e. Zhejiang, Jiangsu and Anhui provinces), and was introduced to Europe in 1984 (OHRNBERGER 2002). Out of over 3700 known eriophyoid species only 110 species of 22 genera have been reported from Poaceae worldwide of which 37 were found on bamboos (Poaceae: Bambuseae) (Amrine \& Stasny 1994, 1996, DAvis et al. 1982, Lin et al. 2000, Xue et al. 2006). Abacarus korosicsomai Ripka, 2011 and Adventacarus turulae Ripka, 2011 were recently described from greenwax golden bamboo (Phyllostachys viridiglaucescens A. Rivière et C. Rivière) in Hungary (RIPKA 2011). These two mite species probably originated in Asia and was introduced to Hungary together with their host plants. 
Keifer (1952) described a new genus and species, Asetacus madronae Keifer, 1952 (Diptilomiopidae) from Arbutus menziesii Pursh. (Ericaceae), of which the female genital coverflap bears a double rank of short ridges, the gnathosoma large and tapering, scapular setae missing, but tubercles of scapular setae present, basiventral femoral seta $b v$ absent on legs I and II, with a short and broad frontal lobe broadly emarginate centrally, and dorsal semiannuli without microtubercles. In Europe, the genus Asetacus currently does not include described species (DE LILLO 2012).

Eriophyoid mites were found on P. iridescens in Hungary and are described as a new genus and species in this paper.

\section{MATERIAL AND METHODS}

The eriophyoid mite fauna of cock bamboo, $P$. iridescens was studied from plant samples collected in plastic bag in Szada, Central Hungary, from a private bamboo plantation, in autumn of 2013. The plant material (including upper and lower surfaces of the leaves, leaf sheaths, stems and buds) was examined under a stereo dissecting microscope (Zeiss Stemi 2000-C). Mites found were put directly into lactic acid with the aid of a bent pin (MANSON 1984), or alternatively in Booster mixture (AMrine \& MANSON 1996), lacto phenol or chloral phenol to clear. Alternative methods for clearing were needed due to the mucous layer and dark colour of specimens which prohibited proper clearing. After clearing the specimens in lactic acid or one of the alternative media (for 8-12 weeks at room temperature to obtain the desired extent of clearing), the mites were mounted in Keifer's F-medium with sorbitol (KeIfER 1975), Hoyer's medium (JePpson et al. 1975) or Heinze polyvinyl alcohol (PVA) medium (Schmutterer 1959). The slide-preparations were dried for about four weeks at room temperature, and then sealed with commercial nail varnish (UPTON 1991). Slide-mounted specimens were studied with a phase contrast compound microscope (Nikon Eclipse E 600) equipped with a drawing tube (Nikon Y-IDT). The morphology of Mucotergum nigrum Ripka gen. et sp. $\mathrm{n}$. was also investigated with the aid of scanning electron microscopy (SEM) (Zeiss EVO 40 XVP) at the Research Centre for Natural Sciences, Hungarian Academy of Sciences, Budapest. Live mites were collected individually with a fine entomological needle from fresh plant parts under a stereomicroscope and placed on double sided adhesive disc glued to the SEM holder without fixation, dehydration and coating. It is a simple and considerably rapid method to take SEM micrographs. The genus classification is based on AMrine et al. (2003) and comparisons were also made with new genera described since that publication. The terminology and setal notation used in the morphological descriptions follow Lindeuist (1996). The number of measured specimens (n) is given within parentheses in the description. All measurements of mites were made according to AMrine and Manson (1996) using an ocular micrometre eyepiece, and are presented in micrometers $(\mu \mathrm{m})$. The holotype measurement precedes the corresponding range of the paratypes, in parentheses. Measurements and means are rounded off to the nearest integer, when necessary. All measurements, unless specified otherwise, refer to the length of the structure. The majority of the setae measured are very fine towards the apex.

Nomenclature of host plants is used according to OHRNBERger (2002) and PLANTS Database (ANonym 2013). 


\title{
RESULTS
}

\author{
Superfamily Eriophyoidea Nalepa, 1898 \\ Family Diptilomiopidae Keifer, 1944 \\ Subfamily Rhyncaphytoptinae Roivainen, 1953
}

\section{Mucotergum Ripka gen. n.}

Diagnosis. Rhyncaphytoptine mites with opisthosoma spindleform and with subequal, microtuberculate dorsal and ventral semiannuli. Tubercles of scapular setae $s c$ and setae $s c$ absent; prodorsal shield with a short and rounded frontal lobe. Prodorsal shield and dorsal semiannuli covered by mucus-like layer. Gnathosoma with setae ep and $d$ present. Coxisternae I and II, and legs I and II with all usual setae, including basiventral femoral seta $b v$ present. Female genitalia not appressed to coxae, genital coverflap divided in two parts, with different ornamentation. Empodium undivided. Caudal lobes normal in size, cone shaped and ornamented with longitudinal ridges ventrally and laterally.

Type species. Mucotergum nigrum Ripka sp. $\mathrm{n}$.

Etymology. The generic name, Mucotergum, is a contraction of the Latin 'mucus', meaning secretion, mucus and discharge, and Latin 'tergum', back, shield, body and surface, which relates to the exceptional layer on the dorsal idiosoma. The gender is neuter.

Differential diagnosis. The new genus Mucotergum is similar to Asetacus Keifer. It clearly differs from Asetacus mainly by having all usual setae, including basiventral femoral seta $b v$ on both leg pairs, the mucus-like cover on the prodorsal shield and dorsal opisthosoma, the uncommonly dark colour, and lack of tubercles of scapular setae sc. The suite of characteristics used to differentiate Mucotergum appear to be significant at generic level but, like some other taxa in the Eriophyoidea, the generic concepts and separation of several taxa assigned to subfamily Rhyncaphytoptinae are thought to be weak and not based on natural groupings (LindQuisT \& AMRINe 1996). So far, only two eriophyoid mites are known, which produce clear liquid secretion on their body: Hoderus globulus (Mohanasundaram, 1981) and Hyborhinus kallarensis Mohanasundaram, 1986 (cit. Manson \& Gerson 1996). Both diptilomiopid species were described from India, and both have tubercles of scapular setae $s c$ and setae sc. The mucus-like secretion on prodorsal shield and dorsal semiannuli is an unusual feature in eriophyoid mites. 


\section{Mucotergum nigrum Ripka sp. $\mathrm{n}$.}

(Figs 1-4)

Diagnosis. Body spindleform; prodorsal shield with granules, weak shield pattern is composed of two faint incomplete, sinuate admedian lines beginning at posterior margin of the shield, two incomplete submedian lines, median line absent; tubercles of scapular setae $s c$ and setae $s c$ absent, dorsal palp genual setae $d$ simple. Prodorsal shield and dorsal semiannuli covered by mucus-like substance. Subequal and microtuberculate dorsal and ventral semiannuli. Coxisternae I and II and legs I and II with all standard setae; empodium entire, 7-8-rayed; female genital coverflap divided in two parts, with different ornamentation. Caudal lobes normal in size, cone shaped, and ornamented with several longitudinal ridges ventrally and laterally.

Description. Female $(n=11)$. Body shiny grey to black, spindleform, curved, 202 (153-210), 64 (60-72) wide, 72 (60-73) thick. Prodorsal shield and dorsal annuli covered by mucus-like substance. Gnathosoma large 46 (39-46), abruptly bent down near base, chelicerae curved and bent down 40 (33-42), pedipalps attenuate, with pedipalp coxal setae ep present, dorsal palp genual setae $d 4$ (4-5), simple; distinct cheliceral retainer 2 (2-3). Prodorsal shield 52 (46-56), 71 (65-72) wide, semicircular; with a short and rounded frontal lobe 3 (2-4); shield ornamentation weak, composed of two faint incomplete, sinuate admedian lines beginning at posterior margin of the shield, two incomplete submedian lines, median line absent; sparsely dashes and granules on the prodorsal shield. Tubercles of scapular setae $s c$ and setae $s c$ absent. Fine granules laterally in rows between shield margin and dorsal coxae of legs I and II, and on dorsal coxae.

Legs with all usual segments and setae present. Leg I 42 (37-45), femur 16 (14-17), owing to a transversal ridge ventrally and laterally seemingly two-segmented and with fine granules, basiventral femoral seta $b v 16$ (15-19), genu $5(5-6)$, antaxial genual seta $l^{\prime \prime}$ $36(28-37)$ close to the distal end, tibia $10(8-11)$, paraxial tibial seta $l^{\prime}$ located at $2 / 3(2 / 3-3 / 4)$ from dorsal base, 5 (5-7), tarsus $6(5-7)$, paraxial, unguinal tarsal seta $u^{\prime} 7$ (6-7), solenidion $\omega 10$ (8-10), blunt, curved, empodium simple, 9 (8-10), 8-rayed (7-9), some specimens with asymmetrical empodium (7/8; 8/9). Leg II 38 (33-40), femur 15 (13-16) with fine granules ventrally, basiventral femoral seta $b v 21$ (20-27), genu 5 (4-6), antaxial genual seta $l^{\prime \prime} 10$ (10-13), very fine, tibia 9 (7-10), tarsus 6 (5-7), paraxial, unguinal tarsal seta $u^{\prime} 5$ (4-6), solenidion $\omega 10$ (9-10) subequal with solenidion $\omega$ on leg I, blunt, curved, empodium simple, 8 (7-9), 7-rayed (7-8), some specimens with asymmetrical empodium (7/8). Longitudinal ridges dorsally and laterally on femora I and II. Distinct spinules distally on femora, genua and tibiae on both leg pairs.

Coxisternae I and II ornamented with granules and short lines; anterolateral setae on coxisternum I, setae $1 b 11$ (10-13), tubercles setae $1 b 15$ (13-19) apart, proximal setae on coxisternum I, setae 1a 24 (20-27), tubercles setae $1 a$ (8-10) apart, proximal setae on coxisternum II, setae $2 a 29$ (26-42), tubercles setae $2 a 24$ (23-31) apart, with curved lines. Subcapitular plate round, with many fine granules. Prosternal apodeme 6 (6-7). Coxigenital area with 7-8 microtuberculate annuli.

Opisthosoma with 64 (56-65) dorsal, 66 (60-69) ventral semiannuli. Dorsal semiannuli with pointed microtubercles on rear annular margin. On ventral semiannuli the micro- 
tubercles are pointed close to the rear annular margin, except for the 8-10 ventral semiannuli from caudal lobes, which are elongate and linear. Opisthosomal setae $c 257$ (30-62), on annulus 9 (9-12), 42 (40-53) apart; opisthosomal setae $d 79$ (51-79), on annulus 22 (20-26), 35 (33-43) apart; opisthosomal setae e 65 (45-65), on annulus 41 (38-44), 25 (23-28) apart; opisthosomal setae $f 37$ (35-40), on annulus 58 (53-62), or 7 (7-9) from the rear, 19 (18-26) apart, all very fine at apex. Opisthosomal seta $h 285$ (85-98), 8 (8-10) apart; seta $h 1$ absent. Caudal lobes normal in size and cone shaped, ornamented with 11-14 longitudinal ridges ventrally and laterally.

Genital plate 22 (15-22), 24 (23-25) wide, a moderate distance behind coxae, not appressed to coxae. Female genital coverflap divided in two parts, anterior part with irregu-

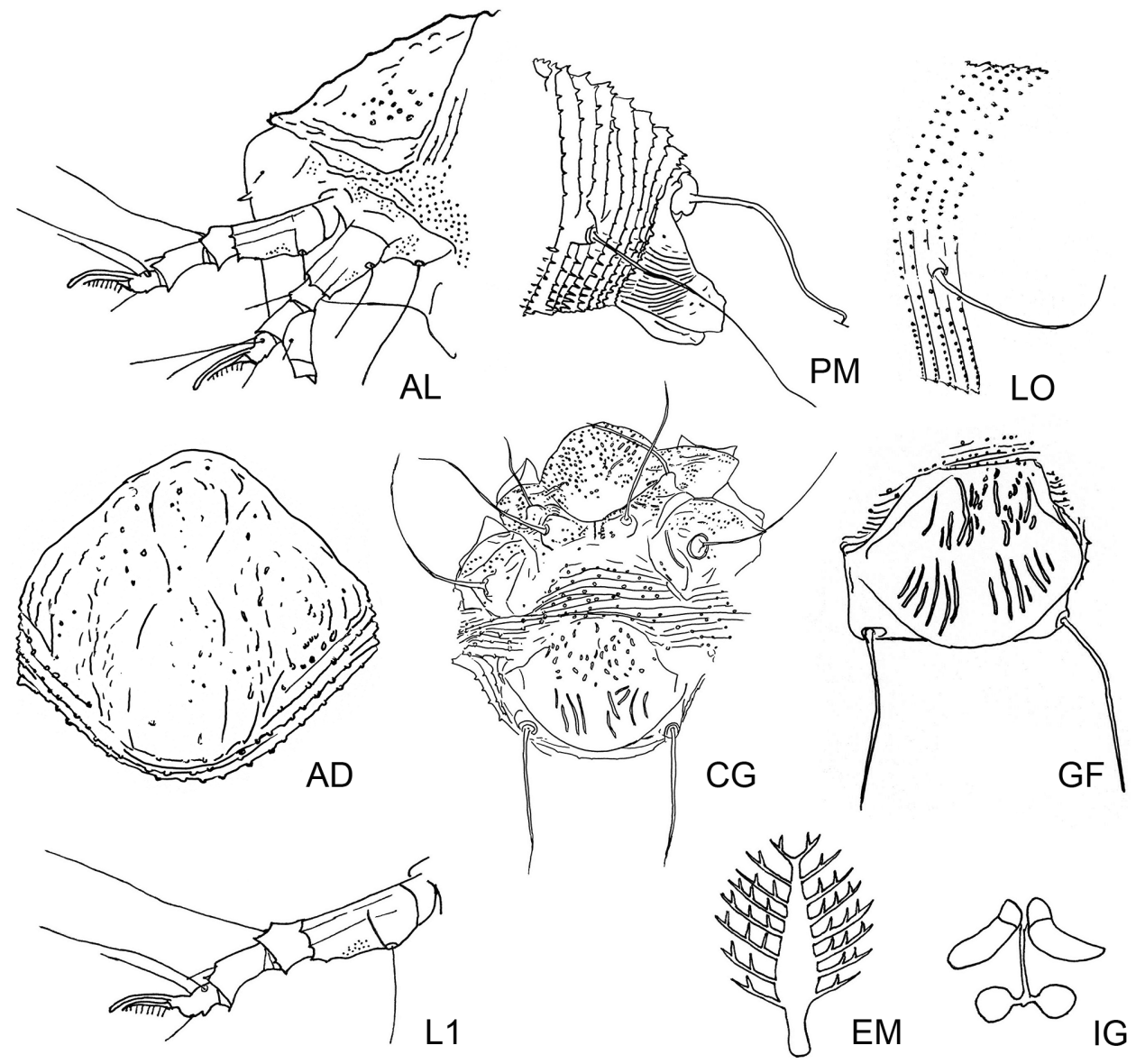

Fig. 1. Mucotergum nigrum Ripka sp. n., semischematic drawing. Abbreviations: $A D=$ prodorsal shield, $\mathrm{AL}=$ lateral view of anterior body region, $\mathrm{CG}=$ female coxigenital region, $\mathrm{EM}=$ empodium of leg I, GF = genital region of female, $\mathrm{IG}=$ internal female genitalia, $\mathrm{L} 1$ = leg I, LO = lateral view of annuli, PM = lateral view of posterior opisthosoma. 
lar short ridges, dashes and lines of granules, or only dashes and granules; posteriorly 10-14 ridges; coxisternal III setae $3 a 23$ (22-31), 19 (18-20) apart.

Male $(n=2)$. Similar to the female, shiny grey to black, spindleform, 163-170, 57 wide, 60 thick. Prodorsal shield and dorsal annuli covered by mucus-like secretion. Gnathosoma 35-37, pedipalps attenuate, dorsal palp genual setae $d 2-3$, simple; distinct cheliceral retainer 1-2. Prodorsal shield 47-49, 60-63 wide, semicircular; with a short, bluntly rounded frontal lobe 3; the shield ornamentation weak, composed of two faint incomplete, sinuate admedian lines beginning at posterior margin of the shield, two incomplete submedian lines, median line absent; sparsely dashes and granules on the prodorsal shield. Tubercles
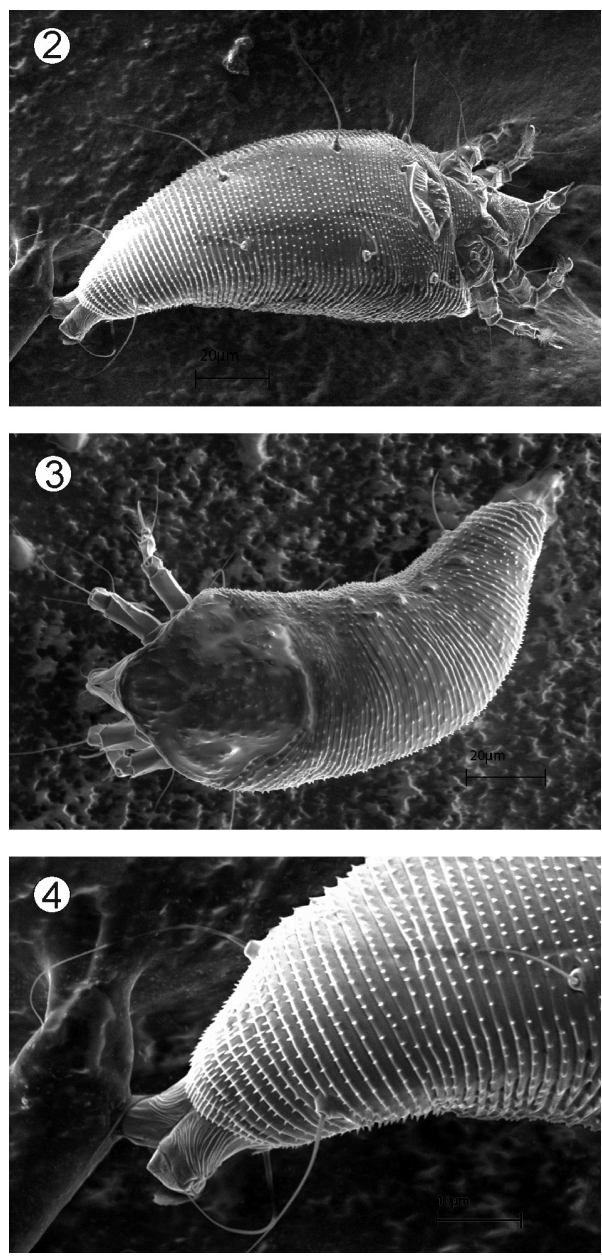

Figs 2-4. Mucotergum nigrum Ripka sp. n.: 2 = ventral aspect of female, $3=$ dorsal aspect of probably female, $4=$ ventral aspect of opisthosoma of female with caudal lobes (SEM micrographs by L. Szabó). of scapular setae $s c$ and setae $s c$ absent. Fine granules laterally in rows between shield margin and dorsal coxae of legs I and II, and on dorsal coxae.

Legs with all usual segments and setae present. Leg I 32-33, femur 12-13, due to a transversal ridge ventrally and laterally seemingly two-segmented and with fine granules, basiventral femoral seta $b v$ 16-17, genu 5, antaxial genual seta $l$ " 25-29 close to the distal end, tibia 7-8, paraxial tibial seta $l^{\prime}$ located at $2 / 3-3 / 4$ from dorsal base, $7-8$, tarsus 6 , paraxial, unguinal tarsal seta $u^{\prime} 5$, solenidion $\omega 9$, blunt, curved, empodium simple, 7, 7-rayed (7-8). Leg II 30-31, femur 12-13; basiventral femoral seta $b v$ 17-18, ventrally with fine granules, genu 5 , antaxial genual seta $l^{\prime \prime} 7-8$ very fine, tibia 6 , tarsus 5 , paraxial, unguinal tarsal seta $u^{\prime} 5$, solenidion $\omega 9$ subequal with solenidion $\omega$ on leg I, blunt, curved, empodium simple, 6, 6-rayed (5-6). Longitudinal ridges dorsally on femora I and II. Distinct spinules distally on femora, genua and tibiae on both leg pairs.

Coxisternae I and II ornamented with granules and short lines; anterolateral setae on coxisternum I, setae $1 b 12$, tubercles setae $1 b 13$ apart, proximal setae on coxisternum I, setae $1 a 15$, tubercles setae $1 a 8$ apart, proximal setae on coxisternum II, setae $2 a 35$, tubercles setae $2 a 20$ apart, with curved lines. Subcapitular plate round, with many fine granules. Prosternal apodeme 5. Coxigenital area with 7-8 microtuberculate annuli.

Opisthosoma with 56-58 dorsal, 63-64 ventral semiannuli. Dorsal semiannuli with pointed microtubercles on rear annular margin. On ventral semiannuli the microtubercles are pointed close to the rear annular 
margin, except for the 5-6 ventral semiannuli from caudal lobes, which are elongate and linear. Opisthosomal setae $c 2$ 28, on annulus 11, 40 apart; opisthosomal setae $d 48$, on annulus 22, 29 apart; opisthosomal setae $e$ 40, on annulus 38, 22 apart; opisthosomal setae $f 25$, on annulus 56, or 7-8 from the rear, 19 apart, all very fine at apex. Seta $h 1$ absent. Caudal lobes normal in size and cone shaped, ornamented with 11-14 longitudinal ridges ventrally and laterally.

Genital part 14, 20 wide, not appressed to coxae. Coxisternal III setae 3a 22-23, 18 apart.

Nymph $(\mathrm{n}=1)$. Similar to the female, shiny grey, spindleform, 170, 70 thick. Gnathosoma 40. Prodorsal shield 45, 53 wide. Tubercles of scapular setae sc and setae sc absent. Legs with all usual segments and setae present. Leg I 28, femur 11, genu 4, antaxial genual seta $l^{\prime \prime} 22$, tibia 6 , paraxial tibial seta $l^{\prime}$ located at $1 / 2$ from dorsal base, 4 , tarsus 4 , solenidion $\omega$ 6, slightly curved, blunt, empodium simple, 6, 6-rayed. Leg II 25, femur 9, basiventral femoral seta $b v 9$, genu 3 , antaxial genual seta $l$ " 7, very fine, tibia 6 , tarsus 5 , solenidion $\omega$ 7, slightly curved, blunt, empodium simple, 6, 6-rayed.

Proximal seta on coxisternum I, 1a 12. Opisthosoma with 52 dorsal, 52 ventral semiannuli. Microtubercles fine points close to the rear annular margins dorsally and ventrally. Opisthosomal setae $d 35$, on annulus 19; setae $e$ 28, on annulus 31; setae $f 20$, on annulus 46, or 6 from the rear. Setae $h 1$ absent. Caudal lobes normal. Coxisternal III setae $3 a 15$.

Larva: not seen.

Host plant. Cock bamboo, Phyllostachys iridescens C.Y. Yao \& S.Y. Chen (Poaceae: Bambuseae).

Relation to the host plant. This vagrant mite was found sparsely on lower side of leaves. Leaf discoloration and slight yellowing were observed.

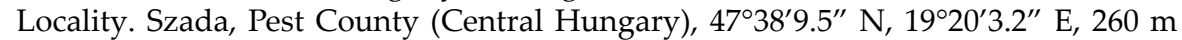
elev. The host grows in a private garden of the third author.

Type material. Holotype female circled with black ink among 12 paratype females and 1 female of Abacarus turulae Ripka, 2011 on one slide, 15 November 2013, slide \# 1333a, coll. A. Neményi. Paratypes: 11 females collected from the same locality and date mounted on slide \# 1333c, coll. A. Neményi, 6 females and 1 male collected from the same locality on 16 September 2013, from underside of leaves, mounted on slide \# 1332K; coll. A. Neményi in the senior author's collection deposited in the Department of Pest Management Development and Coordination, Directorate of Plant Protection, Soil Conservation and Agrienvironment, National Food Chain Safety Office, Budapest, Hungary. The new species was found together with the specimens of Abacarus turulae Ripka covered with wax plates. A. turulae was collected from the underside of the leaves, among hairs near the midrib, close to the leaf base.

Etymology. The specific name, nigrum, is derived from the Latin 'nigrum', meaning blackish or dark, relating to the uncommon colour of the mite.

Differential diagnosis. The new species herein described is similar to Asetacus linderae Wang, Wei et Yang described from Lindera sp. (Lauraceae) (WANG et al. 2010). The scapular tubercles set ahead of rear shield margin, prodorsal shield sculptured with granules and 12 irregular lines, the genital coverflap sculptured with basal 23 and distal 26 longitudinal ridges. It has 6-rayed empodium, and seta $h 1$. The basiventral femoral setae absent on leg 
I and leg II. Whereas characters of Mucotergum nigrum Ripka gen. et sp. $\mathrm{n}$. are the tubercles of scapular setae $s c$ and setae $s c$ absent, the 7-8-rayed empodium, irregular short ridges, dashes and lines of granules, or only dashes and granules anteriorly, and 10-14 ridges posteriorly on genital coverflap, pointed microtubercles on annuli, presence of basiventral femoral setae $b v$ on both leg pairs, seta $h 1$ absent, and especially mucus-like secretion on prodorsal shield and dorsal semiannuli. Caudal lobes normal in size and cone shaped, and ornamented with longitudinal ridges ventrally and laterally. Its host plant is Phyllostachys iridescens, leaf discoloration occurred.

*

Acknowledgements - Thanks are expressed to two anonymous reviewers for their contributions to improving the paper; Mrs Katalin Tóth Csáki, librarian (National Food Chain Safety Office, Budapest), for providing reprints of some papers which were not otherwise obtainable by the senior author. The author is grateful to Dr László Szabó (Research Centre for Natural Sciences, Hungarian Academy of Sciences, Budapest, Hungary) for help with the preparation of specimens for SEM micrographs. The author is indebted to $\mathrm{Mr}$ Ede Böszörményi (National Food Chain Safety Office, Budapest) for the linguistic revision of an initial draft of the manuscript. This research was supported by OTKA 108663 (J. Kontschán) and EMMI 8526-5/2014/TUDPOL SZIE.

\section{REFERENCES}

Amrine, J. W., Jr. \& Manson, D. C. M. (1996) Preparation, mounting and descriptive study of eriophyoid mites. Pp. 383-396. In: Lindquist, E. E., SAbelis, M. W. \& Bruin, J. (eds): Eriophyoid mites - their biology, natural enemies and control. Elsevier, World Crop Pests, 6. Amsterdam, The Netherlands. doi: 10.1016/S1572-4379(96)80023-6

Amrine, J. W., JR. \& Stasny, T. A. (1994) Catalog of the Eriophyoidea (Acarina: Prostigmata) of the World. Indira Publishing House, West Bloomfield, USA, 798 pp. doi: 10.1080/ 01647959608684108

Amrine, J.W., Jr. \& StASnY, T.A. (1996) Corrections to the catalog of the Eriophyoidea (Acarina: Prostigmata) of the World. International Journal of Acarology 22: 295-304. doi: $10.1080 / 01647959608684108$

Amrine, J. W., JR., Stasny, T. A. H. \& Flechtmann, C. H. W. (2003) Revised keys to world genera of Eriophyoidea (Acari: Prostigmata). Indira Publishing House, West Bloomfield, USA, 244 pp.

Anonym (2013) PLANTS Database. USDA Natural Resources Conservation Service. http:// plants.usda.gov/java/ (accessed 18 December 2013).

Davis, R., Flechtmann, C. H. W., Boczek, J. H. \& Barké, H. E. (1982) Catalogue of eriophyid mites (Acari: Eriophyoidea). Warsaw Agricultural University Press, Warsaw, 254 pp.

De Lillo, E. (2012) Fauna Europaea: Eriophyoidea. In: Magowski, W. Ł. (ed.): Fauna Europaea: Acari: Acariformes. Fauna Europaea version. 2.4. http://www.faunaeur.org (accessed 29 July 2014). 
Huang, K.-W. (2001) Eriophyoid mites of Taiwan: description of eighty-six species from Tengchih area (Acarina: Eriophyoidea). Bulletin of the National Museum of Natural Science 14: 1-84.

Jeppson, L. R., Keifer, H. H. \& Baker, E. W. (eds) (1975) Mites injurious to economic plants. University of California Press, Berkeley, Los Angeles, London, 615 pp.

KeIfer, H. H. (1952) Eriophyid studies XVIII. The Bulletin Department of Agriculture State of California, USA 41: 31-42.

Keifer, H. H. (1975) Eriophyoidea Nalepa. Pp. 327-533. In: Jeppson, L. R., Keifer, H. H. \& Baker, E. W. (eds): Mites injurious to economic plants. University of California Press, Berkeley, Los Angeles, London.

KIRÁLY, G. (ed.) (2009) Új magyar füvészkönyv. Magyarország hajtásos növényei. Határozókulcsok. [New Hungarian Herbal. The Vascular Plants of Hungary. Identification Key.]. Aggteleki Nemzeti Park Igazgatóság, Jósvafö, 616 pp.

Lin, J.-Z., Zhang, Z.-Q., Zhang, Y.-X., Liv, Q.-Y. \& Ji, J. (2000) Checklist of mites from moso bamboo in Fujian, China. Systematic and Applied Acarology Special Publications 4: 81-92. doi: $10.11158 /$ saasp.4.1.9

Lindquist, E. E. (1996) External anatomy and notation of structures. Pp. 3-30. In: Lindeuist, E. E., Sabelis, M. W. \& Bruin, J. (eds): Eriophyoid mites - their biology, natural enemies and control. Elsevier, World Crop Pests, 6. Amsterdam, The Netherlands. doi: 10.1016/ S1572-4379(96)80003-0

Lindquist, E. E. \& Amrine, J. W., JR. (1996) Systematics, diagnoses for major taxa, and keys to families and genera with species on plants of economic importance. Pp. 33-87. In: Lindquist, E. E., SAbelis, M. W. \& Bruin, J. (eds): Eriophyoid mites - their biology, natural enemies and control. Elsevier, World Crop Pests, 6. Amsterdam, The Netherlands. doi: 10.1016/S1572-4379(96)80004-2

Manson, D. C. M. (1984) Eriophyoidea except Eriophyinae (Arachnida: Acari). Fauna New Zealand, No. 4. Sci. Inform. Publ. Centre, DSIR, Wellington, New Zealand, 142 pp.

Manson, D. C. M. \& Gerson, U. (1996) Web spinning, wax secretion and liquid secretion by eriophyoid mites. Pp. 251-258. In: Lindquist, E. E., Sabelis, M. W. \& Bruin, J. (eds): Eriophyoid mites - their biology, natural enemies and control. Elsevier, World Crop Pests, 6. Amsterdam, The Netherlands. doi: 10.1016/S1572-4379(96)80016-9

Ohrnberger, D. (2002) The bamboos of the world: Annotated nomenclature and literature of the species and the higher and lower taxa. Elsevier, 596 pp. (accessed 4 February 2014).

Ripka, G. (2007) Checklist of the eriophyoid mite fauna of Hungary (Acari: Prostigmata: Eriophyoidea). Acta Phytopathologica et Entomologica Hungarica 42: 59-142. doi: 10.1556/APhyt.42.2007.1.7

RIPKA, G. (2008) Additional data to the eriophyoid mite fauna of Hungary (Acari: Prostigmata: Eriophyoidea). Acta Phytopathologica et Entomologica Hungarica 43: 143-161. doi: 10.1556/APhyt.43.2008.1.15

RipkA, G. (2011) A new genus, Adventacarus and new Abacarus species from Hungary (Acari: Prostigmata: Eriophyoidea). Acta Phytopathologica et Entomologica Hungarica 46: 139-149. doi: 10.1556/APhyt.46.2011.1.11

Schmutterer, H. (1959) Schildläuse oder Coccoidea. I. Deckelschildläuse oder Diaspididae. In: DAhL, M. \& Bischoff, H. (eds): Die Tierwelt Deutschlands und der angrenzenden Meeresteile. 45. Gustav Fischer Verlag, Jena, 260 pp.

Upton, M. S. (1991) Methods for collecting, preserving, and studying insects and allied forms. The Australian Entomological Society, Brisbane. Misc. Publ. No. 3., 86 pp. 
WANG, G.-Q., WeI, S.-G. \& YANG, D. (2010) Description of a new species of Asetacus from South China and a redescription of Rhyncaphytoptus acer (Acari: Diptilomiopidae: Rhyncaphytoptinae). Annales Zoologici (Warszawa) 60: 627-632. doi: 10.3161/ $000345410 \times 550481$

Xue, X.-F., Song, Z.-W., Amrine, J. W., JR. \& Hong, X.-Y. (2006) Eriophyid mites (Acari: Eriophyoidea) on bamboo from China, with descriptions of three new species from the Qinling Mountains. Annals of the Entomological Society of America 99: 1057-1063. doi: 10.1603/0013-8746(2006)99\%5B1057:EMAEOB\%5D2.0.CO;2

Revised version received August 29, 2014, accepted December 6, 2014, published April 30, 2015 